\title{
Iranian Consensus Recommendations for Treatment of Myasthenia Gravis
}

Shahriar Nafissi, $\mathrm{MD}^{1 *}$; Ali Asghar Okhovat, $\mathrm{MD}^{1,2}$; Farnaz Sinaei, $\mathrm{MD}^{1}$; Behnaz Ansari, $\mathrm{MD}^{3}$; Hormoz Ayramloo, $\mathrm{MD}^{4}$; Keyvan Basiri, MD³; Reza Boostani, MD5; Bahram Haghi Ashtiani, MD'; Payam Sarraf, MD; Farzad Fatehi, MD $^{1}$

\author{
${ }^{1}$ Neurology Department, Shariati Hospital, Iranian Neuromuscular Research Center (INMRC), Tehran University of Medical Sciences, \\ Tehran, Iran \\ ${ }^{2}$ Neurology Department, Sina Hospital, Tehran University of Medical Sciences, Tehran, Iran \\ ${ }^{3}$ Department of Neurology, Isfahan University of Medical Sciences, Isfahan, Iran \\ ${ }^{4}$ Department of Neurology, Tabriz University of Medical Sciences, Tabriz, Iran \\ ${ }^{5}$ Neurology Department, Ghaem Hospital, Mashhad University of Medical Sciences, Mashhad, Iran. \\ ${ }^{6}$ Department of Neurology, Firoozgar Hospital, Iran University of Medical Sciences, Tehran, Iran \\ ${ }^{7}$ Neurology Department, Imam-Khomeini Complex Hospital, Tehran University of Medical Sciences, Tehran, Iran
}

\begin{abstract}
Myasthenia gravis (MG) is an immune-mediated potentially treatable disease in which rapid diagnosis and proper treatment can control symptoms. Treatment should be individualized in each patient according to distribution (ocular or generalized) and severity of the weakness, antibody status, thymus pathology, patient comorbidities, and preferences. A group of Iranian neuromuscular specialists have written these recommendations to treat MG based on national conditions. Four of the authors performed an extensive literature review, including PubMed, EMBASE, and Google Scholar, from 1932 to 2020 before the central meeting to define headings and subheadings. The experts held a 2-day session where the primary drafts were discussed point by point. Primary algorithms for the management of MG patients were prepared in the panel discussion. After the panel, the discussions continued in virtual group discussions, and the prepared guideline was finalized after agreement and concordance between the panel members. Finally, a total of 71 expert recommendations were included. We attempted to develop a guideline based on Iran's local requirements. We hope that these guidelines help healthcare professionals in proper treatment and follow-up of patients with MG.

Keywords: Consensus, Myasthenia Gravis, Iran, Therapy

Cite this article as: Nafissi S, Okhovat AA, Sinaei F, Ansari B, Ayramloo H, Basiri K, et al. Iranian consensus recommendations for treatment of myasthenia gravis. Arch Iran Med. 2022;25(1):37-49. doi: 10.34172/aim.2022.07
\end{abstract}

Received: January 18, 2021, Accepted: May 19, 2021, ePublished: January 1, 2022

\section{Introduction}

Myasthenia gravis (MG) is an auto-immune neuromuscular junction disorder manifested by weakness of the extraocular, limb, bulbar, and respiratory muscles. Its prevalence is approximately 1 in 5000. Although MG can affect patients of all ages, the prevalence is higher in young women and older men. Over the past 50 years, an increasing number of patients are being diagnosed due to better diagnostic tools and more patients are surviving due to improved treatment options and increased life expectancy. ${ }^{1}$

Treatment should be individualized in each patient according to distribution (ocular or generalized) and severity of the weakness, antibodies status, thymus pathology, patient comorbidities, and patient preferences. ${ }^{2,3}$ For MG patients refractory to conventional immunosuppression therapy, biologic agents such as monoclonal antibodies are highly promising. ${ }^{4-6}$ A group of Iranian neuromuscular specialists have written these recommendations for the treatment of MG based on national conditions.

\section{Diagnosis}

Based on age, the presence and type of antibodies, the pathology of the thymus, and the region of muscles involved in MG, the patients are divided into the following categories:

1. Ocular MG

2. Early-onset generalized non-thymomatous ACRpositive MG

3. Late-onset generalized non-thymomatous ACRpositive MG

4. Thymomatous MG

5. Muscle-specific tyrosine kinase (MuSK)-positive MG

6. Generalized seronegative MG

MG is assumed in patients complaining of diurnal variation of muscle weakness. When there is a clinical diagnosis of MG, the diagnosis should be confirmed by paraclinical assays. These include electrodiagnostic studies (EDX), pharmacologic testing, and serum antibodies assay. EDX includes slow (2 to $5-\mathrm{Hz}$ ) repetitive nerve stimulation (RNS) and single-fiber electromyography (SFEMG). EDX is beneficial in double-seronegative MG patients. ${ }^{7}$ The most sensitive test for diagnosis of MG is 
SFEMG, and, when studied in weak muscles, positive results are recorded in nearly all patients. However, an abnormal SFEMG (increased jitter or blocking) is not specific for MG and, apart from other diseases of the neuromuscular junction, can be found in motor neuron disease or myopathies. ${ }^{8}$

A positive response to ChEIs (Tensilon test), as unambiguous quantifiable muscle weakness improvement, strongly supports MG's diagnosis although it is not specific. The positive responses to the edrophonium test are around $90 \%$ in $\mathrm{MG} .{ }^{9}$ In MuSK MG, ChEI injection is often unsuccessful, provokes cramp and fasciculations, and may even induce clinical worsening. ${ }^{10}$ A positive Tensilon test can be seen in congenital myasthenic syndromes, Lambert-Eaton myasthenic syndrome, Amyotrophic lateral sclerosis (ALS), and Guillain-Barré syndrome. ${ }^{11}$

Serological testing is one of the diagnostic tools in a patient suspected of having MG. AChR-binding antibodies to MG are highly specific $(97 \%-99 \%){ }^{12}$ and are positive in about $80 \%$ of generalized MG patients, and $50 \%$ of patients with ocular MG. ${ }^{1}$ In very rare conditions, falsepositive results have been seen including in some patients with Guillain-Barré syndrome, asymptomatic thymoma, and patients with ALS. ${ }^{1,13}$ If AChR antibodies are negative, MuSK antibodies are tested that are present in around one-third of seronegative generalized MG patients. ${ }^{14}$ In approximately $15 \%-20 \%$ of patients, both antibodies are negative (double seronegative). Antibodies to lowdensity lipoprotein receptor-related protein 4 (LRP4) and agrin have been described in some double seronegative patients. ${ }^{15,16}$

\section{Methods}

A group of neuromuscular experts with particular interest and experience in the management of MG participated in developing this guideline. Search terms were created. Four of the authors performed an extensive literature review, including PubMed, EMBASE, and Google Scholar, from 1932 to 2020 before the central meeting to define headings and subheadings. Each panel member prepared a draft on an assigned heading before the consensus session.

The experts held a 2-day session where the primary drafts were discussed point by point. Primary algorithms for the management of MG patients were prepared in the panel discussion. In case of discordance, the matter was subjected to vote and settled once more than two-thirds of the participants voted positively. After the Panel, the discussions continued in virtual group discussions, and the prepared guideline was finalized after agreement and concordance among the panel members.

\section{Treatment}

\section{Symptomatic Treatment}

The efficacy of ChEIs in treating MG has not yet been evaluated in a randomized controlled trial (RCT). However, there are observational studies, including case series and daily clinical experiences, regarding the beneficial effect of this drug in MG. ${ }^{17}$ There is only one RCT to compare the effects of intranasal neostigmine and placebo in MG with significant clinical and electromyographic improvement for intranasal neostigmine. ${ }^{18}$ Pyridostigmine is started at a $30-60 \mathrm{mg}$ dose three times daily. The dosage is then gradually increased to keep the symptoms minimum, with a maximum dose of $120 \mathrm{mg}$ every three hours (960 $\mathrm{mg} / \mathrm{d}){ }^{2}$ For pediatric use, the initial prescription is 0.5 to $1 \mathrm{mg} / \mathrm{kg}$, and the highest daily dose is $7 \mathrm{mg} / \mathrm{kg}$ separated into five to six doses. ${ }^{19,20}$ Improvement does not occur on pyridostigmine in some MuSK-MG patients, and standard doses may cause marked nicotinic side effects, such as diffuse fasciculations and cramps. ${ }^{21}$

In patients with mild symptoms, ChEIs may suffice as the sole treatment. ${ }^{2}$ Typically, generalized MG patients need pyridostigmine with prednisone for adequate clinical improvement. $^{2}$ Corticosteroids or immunosuppressive therapy should be initiated in all patients with MG who have not received adequate pyridostigmine improvement after optimal dosing. ${ }^{3}$

\section{Recommendations}

- ChEIs should be tried as the initial treatment for all subtypes of MG.

- Particular caution should be made in patients with myasthenic crisis and MuSK MG.

- $\quad$ All ChEIs are stopped while the patient is intubated. However, some experts believe ChEIs might be continued if excessive bronchial secretions are not a significant concern.

- We prefer to initiate immunomodulation therapy if $240 \mathrm{mg}$ of daily pyridostigmine does not achieve adequate symptom control.

- We suggest starting pyridostigmine 30-60 mg three times daily and then level up the dose gradually to keep the symptoms to a minimum, with a maximum dose of $120 \mathrm{mg}$ every three hours (960 mg).

- Pyridostigmine dose should be adjusted as required based on symptoms. The ultimate goal of immunotherapy is to improve symptoms and minimize the required dose of symptomatic therapy.

\footnotetext{
Intravenous Immunoglobulin (IVIg) and Plasma Exchange (PLEX)

Several studies have demonstrated the efficacy of $\operatorname{IVIg}^{22-29}$ and PLEX ${ }^{30-43}$ in MG. They have been used both in the MG crisis or exacerbation, ${ }^{27,28}$ as maintenance therapies, ${ }^{24,25,44}$ in patients who do not tolerate corticosteroids or other steroid-sparing drugs or when there is a contraindication. ${ }^{45}$ The choice of IVIg or PLEX depends on general information of the disorders, the therapeutic effects, and the unwanted side effects of each of these approaches. ${ }^{46}$ A randomized trial in 1997 comparing IVIg and PLEX showed that the myasthenic severity score variation was comparable in both groups; however, IVIg tolerance was significantly better than PLEX. ${ }^{47}$ In another retrospective study on patients with MG crisis (in 54 crises), PLEX was
} 
considerably better in ventilatory improvement at two weeks and one-month functional outcome, although with a higher complication rate. ${ }^{48}$

In another study, the efficacy of PLEX vs. IVIg was compared in moderate to severe MG $(n=84),{ }^{49}$ and both were equally effective in reducing QMGS. In the meta-analysis (10 articles eligible for the analysis for MG patients), PLEX or IVIg were similar in terms of efficacy or safety and hospital stay length and ventilatory support time. ${ }^{46}$

\section{Recommendations}

- PLEX and IVIg are indicated in (1) MG crisis (respiratory insufficiency), or severe exacerbation; (2) when a patient with significant bulbar or respiratory dysfunction is being prepared for an emergent surgery; (3) maintenance therapy for the refractory forms, or when corticosteroids are contraindicated (such as in the patients with uncontrollable diabetes mellitus).

- Choosing between PLEX and IVIg should be individualized according to each center's experience, availability, cost, and the patient's condition - e.g. in patients with a history of cardio-embolic events or renal failure, PLEX may be preferable; however, in patients with sepsis, IVIg may be superior to PLEX. With PLEX, the risk of hemodynamic instability and venous access problems is always a concern.

\section{Thymectomy}

There is general agreement on thymectomy in thymomatous- $\mathrm{MG}^{2,3}$; however, for decades, there have been controversies about non-thymomatous patients due to the lack of randomized controlled trials. ${ }^{50-52}$ In a multi-center, randomized, rater-blinded clinical trial, 126 AChR + generalized MG patients, aged 18-65 years, were randomized to either thymectomy plus prednisone versus prednisone alone. The thymectomy arm had a lower score in average QMG and lower prednisone dose requirement in a 3-year follow-up. ${ }^{53}$ The extension study evaluated the outcome after five years of follow-up. Thymectomy plus prednisone continued to confer benefits in generalized non-thymomatous $\mathrm{AChR}+\mathrm{MG}$ patients compared with prednisone alone. ${ }^{54}$

CT scan with intravenous contrast is the imaging modality of choice for assessing thymus abnormalities. ${ }^{2,55}$ Thymectomy for MG is an elective surgery; however, it must be done as soon as possible in thymomatous patients, and it should be done when the patient is in a stable condition. The benefit of thymectomy is not immediate and appears in the following $1-2$ years. ${ }^{56}$ The current belief is that the benefits of thymectomy are most significant if performed within the first three years of initial symptoms. ${ }^{57,58}$ One study in Iran showed that early thymectomy (less than one year after MG diagnosis) is beneficial. ${ }^{59}$ Four operative procedures are used for thymectomy: (1) Transcervical; (2) minimally invasive (video-assisted [VATS] and robot-assisted); (3) transsternal; (4) mixed transcervicaltranssternal. VATS and robotic methods seem to profit comparable outcomes to more aggressive techniques, even in MG with thymoma. ${ }^{60,61}$ However, it is unknown whether the benefit achieved by extended transsternal thymectomy can also be achieved by minimally invasive approaches such as VATS. ${ }^{51}$

\section{Recommendations}

- Chest CT with contrast must be done in all MG patients with stable conditions. Chest MRI should be considered if the contrast injection is contraindicated. Whether MuSK + MG patients require chest imaging is not clear

- Thymectomy is recommended for generalized nonthymomatous AchR + MG patients aged 18 through 65 and all thymomatous MG patients (Figure 1).

- In juvenile MG, thymectomy decisions should be individualized based on the patient's clinical condition and VATS availability.

- There is no consensus on patients with generalized MG with double seronegative antibody status.

- Thymectomy is not indicated in MuSK + MG patients.

- Thymectomy is not recommended in patients with ocular MG unless there is evidence of thymoma on chest CT scan.

- In patients with the myasthenic crisis or patients with severe weakness and bulbar dysfunction, the operation must be performed after stabilization (using PLEX, IVIg, or other medications)

- It is not clear whether less-invasive methods such as VATS are as effective as trans-sternal thymectomy

\section{Immunosuppressive Therapy in Management of MG Corticosteroids}

Like other autoimmune diseases, immunosuppressive therapy is the mainstay of MG treatment, most notably with corticosteroids (Algorithm 1). Although the number of double-blind, placebo-controlled studies providing credible clinical evidence about the effectiveness of corticosteroids in MG is limited, many retrospective studies have shown its effectiveness in alleviating symptoms in more than $80 \%$ of myasthenic patients. ${ }^{2,62}$

Several corticosteroid regimens have been recommended for MG. One of the most frequently used regimens is high-dose prednisolone $(1-1.5 \mathrm{mg} / \mathrm{kg} / \mathrm{d})$. In this regimen, clinical improvement is expected within 2-4 weeks, although complete remission might not ensue until several months later. After observing a prompt clinical response, the corticosteroid dose would be lowered gradually, at a rate of $5-10 \mathrm{mg} / \mathrm{mon} .{ }^{1,62}$ The primary concern with the high dose regimen is clinical deterioration in the first few days of the treatment. Therefore, the protocol could only be administered in an inpatient setting.

The second approach involves low-dose (5-10 mg/d) corticosteroids administration with subsequent escalation by $5-10 \mathrm{mg}$ weekly until the symptoms are resolved or the 


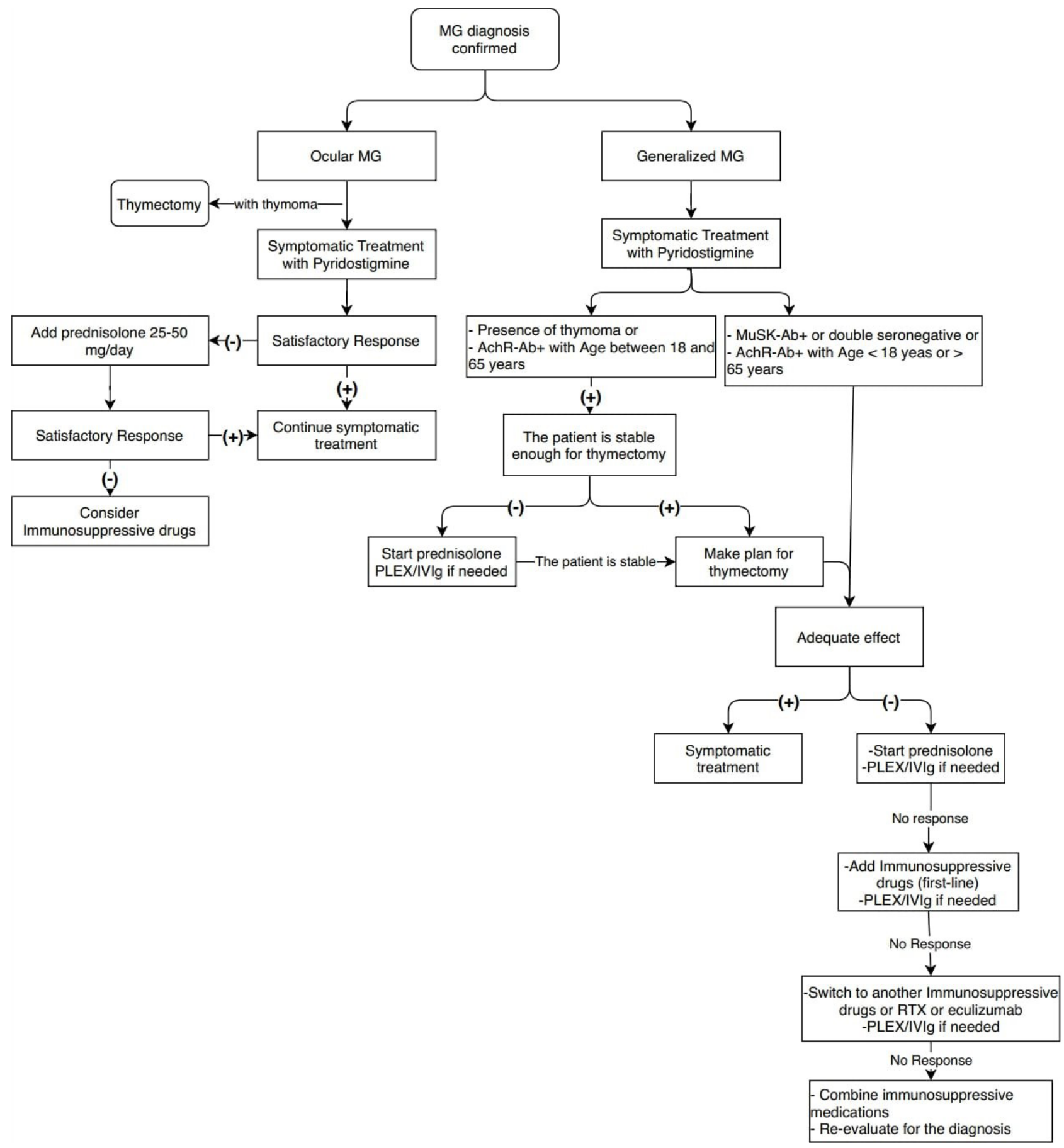

Figure 1. Algorithm of MG treatment.

maximum dose of $1-1.5 \mathrm{mg} / \mathrm{kg} / \mathrm{d}$ reached. Corticosteroids should be tapered upon the induction of the clinical response. The main benefit of this approach is the lower occurrence of the above-mentioned initial deterioration, though at the expense of delayed remission. ${ }^{1}$

Some experts have recently pursued a third approach: a medium dose of prednisone (e.g. $20 \mathrm{mg} / \mathrm{d}$ ) is administered first. Further escalation will be considered if clinical remission is not evident at monthly clinical evaluations. Like the two approaches mentioned above, corticosteroids should be tapered as soon as induction is achieved. ${ }^{2}$

As a fourth approach, corticosteroid pulse therapy has been used to induce remission in myasthenic patients.
However, clinical studies are scarce, so pulse therapy has not gained much attention as a treatment choice in $\mathrm{MG}{ }^{63}$

In patients with ocular or mild forms of $\mathrm{MG}$, corticosteroids are used as the sole immunosuppressant. ${ }^{2}$ However, most MG patients, especially those with moderate and severe disease, will need higher corticosteroid doses for long periods. Adverse effects might outweigh the benefits in this situation ${ }^{1,2}$ and addition of immunosuppressive drugs is reasonable.

\section{Non-steroidal Immunosuppressive Drugs}

The efficacy of azathioprine (AZT), mycophenolate mofetil, methotrexate, tacrolimus, and cyclophosphamide 
has been investigated in double-blind placebo-controlled clinical trials.

AZT is the most acceptable steroid-sparing agent in MG treatment. ${ }^{64}$ In a double-blind randomized trial of 34 patients, the prednisolone dose and clinical outcome were assessed over a follow-up period of 3 years in patients taking prednisolone and AZT and those taking prednisolone and placebo. The placebo group was more prone to relapses and failure to remit. ${ }^{64}$ Delayed clinical response (until at least one year) is believed to be the primary concern with the use of AZT and the need for periodic liver function and $\mathrm{CBC}$ monitoring. ${ }^{2}$

Mycophenolate mofetil is another potentially effective immunosuppressive with the main advantage of a favorable safety profile leading to high compliance. ${ }^{1,2}$ This medication is found to be potentially effective by some neuromuscular experts, although it has failed to yield significant results in 2 clinical trials ${ }^{65,66}$; however, trial failure may be due to a short follow-up period ( 36 weeks in one study and 12 weeks in the other) and simultaneous use of prednisolone. Nevertheless, its favorable safety profile leading to high compliance makes it a good alternative steroid-sparing option.

The methotrexate trial also showed non-significant results with a dose of $20 \mathrm{mg}$ weekly over 12 months. ${ }^{67}$ The only trial with tacrolimus also showed no significant difference between tacrolimus and placebo group over 28 weeks, although in secondary analyses, some steroidsparing effects of tacrolimus were suggested. ${ }^{68}$

Monthly intravenous cyclophosphamide has been investigated in $23 \mathrm{MG}$ patients with poor disease control or corticosteroid-related side effects for 12 months. Favorable results were achieved in muscle force, steroid and pyridostigmine dose reductions, and bulbar muscle weakness in the cyclophosphamide group. ${ }^{69}$

Several clinical trials have been performed on cyclosporine between 1987 and 2010, and most of them have suggested the efficacy of cyclosporine in MG; however, no double-blind placebo-controlled trial could be found. ${ }^{70,71}$

\section{Monoclonal Antibodies and Emerging Therapies}

Rituximab is a newly introduced promising option in MG treatment. ${ }^{4-6}$ The efficacy of RTX in MuSK + MG and AchR $+M G$ is well established. ${ }^{72,73}$ Availability, relative safety, and ease of administration of rituximab have led to a significant drop in cyclophosphamide use in MG. Currently, there is no consensus on the inclusion of rituximab as a therapeutic choice in MG. However, treatment of resistant disease is probably the main indication for rituximab in MG. ${ }^{1,2}$

Ocrelizumab is a new generation fully humanized anti-CD20 monoclonal antibody, which probably has the same effects as rituximab. ${ }^{74}$ After a successful clinical trial of eculizumab (a monoclonal complement inhibitor antibody), FDA has approved Soliris for refractory

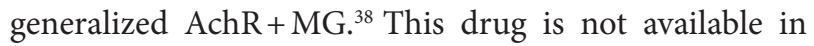

Iran yet. Ravulizumab, which binds the complement protein C5like eculizumab, is under study in phase III clinical trial. Ravulizumab has a longer half-life than eculizumab. ${ }^{76}$

Zilucoplan is a subcutaneously-administered C5 inhibitor peptide, and the results of phase 2 trials on Zilucoplan have been favorable in reducing QMG and MG-ADL. ${ }^{77}$ Efgartigimod, the neonatal Fc-receptor $(\mathrm{FcRn})$ antagonist, shortens IgG half-life. ${ }^{78}$ In phase II clinical trial, all MG patients treated with efgartigimod exhibited fast reduction in overall IgG and anti-AChR autoantibody levels, and $75 \%$ of the patients showed fast and long-lasting disease control. ${ }^{78}$

\section{Ongoing Monitoring in MG Treatment}

Laboratory test monitoring during MG treatment differs based on the type of immunosuppressant treatment. Bone mineral densitometry must be performed in the first six months of treatment for all patients above 40 years of age and any patients with other osteoporosis risk factors. Repeat bone mineral densitometry should be performed every 1-3 years during treatment.

Preceding the start of treatment, one must consider if vaccinations are needed and laboratory tests should be evaluated.Moreover,somelaboratorytestsarespecifictoeach distinct immunosuppressant with regular testing ${ }^{79}$ :

AZT; CBC with differential, creatinine, liver function tests (LFTs), Mycophenolate mofetil; CBC with differential, Methotrexate; CBC with differential, creatinine, LFTs. Rituximab; CBC with differential and immunoglobulins before each cycle, hepatitis B PCR every 6 months if core antibody $(\mathrm{HBc} \mathrm{Ab})$ is positive, Cyclosporine; $\mathrm{CBC}$ with differential, creatinine, LFTs, lipid panel, Cyclophosphamide; $\mathrm{CBC}$ with differential and creatinine. $^{79}$

\section{Recommendations}

- In mild generalized AchR $+M G$, start treatment with ChEIs plus thymectomy if indicated. Add prednisolone if symptoms persist or exacerbate after thymectomy ( Algorithm 1).

- In moderate-severe generalized AchR+MG, start treatment with ChEIs plus prednisolone as well as thymectomy if indicated.

- Add AZT to corticosteroids when: (1) significant steroid side effects occur; (2) response to an acceptable corticosteroid dose is insufficient; (3) the patient is steroid-dependent (relapse of symptoms with reduction of corticosteroid dose) with a dose so high that long-term maintenance is not acceptable.

- If AZT or other immunosuppressives such as mycophenolate mofetil, cyclosporine, or tacrolimus are ineffective (after 9-12 months of treatment), replace with rituximab.

- In moderate-severe generalized $\mathrm{AchR}+\mathrm{MG}$, when waiting for the effect of immunosuppressives, treat exacerbations with intermittent IVIg or PLEX. 
- If the patient is refractory to previous agents, consider monthly IVIg; if non-responsive, consider cyclophosphamide, or eculizumab (in nonthymomatous generalized AchR + MG).

- In patients who are contraindicated for corticosteroids, it is possible to start immunosuppressive as an initial immunosuppressive agent.

- After treatment with PLEX/IVIg,in MG crisis, consider augmentation of long-term immunosuppression with prednisone or other immunosuppressives if necessary.

\section{MG Treatment in Specific Settings Ocular MG}

ChEIs alone usually will not resolve the ocular symptoms. Most guidelines recommend oral corticosteroids if symptoms are functionally restricting or worrying to the patient. ${ }^{80,81}$ A randomized, double-blind trial (EPITOME) has reported good results for oral prednisolone in the improvement of ocular symptoms. ${ }^{82}$ A inferior dose than in generalized MG $(25-30 \mathrm{mg} / \mathrm{d})$ can be often effective. ${ }^{80,81}$ Almost one-third of the patients need treatment for a long-term period.

\section{Recommendations}

- ChEIs are recommended as the initial treatment for ocular MG.

- We recommend corticosteroids at a dose of 25$30 \mathrm{mg} / \mathrm{d}$ in ocular MG unresponsive to ChEIs and increasing the dose to $1 \mathrm{mg} / \mathrm{kg}$ if the response is not optimal. As soon as the optimal response is achieved, tapering of corticosteroids should be initiated slowly (e.g. 2.5 to $5 \mathrm{mg}$ monthly) to the lowest tolerable dose.

- In case of significant residual symptoms, corticosteroid-sparing immunosuppressive drugs could be required after corticosteroids alone are unsuccessful, contraindicated, or not tolerated.

\section{Anti-MuSK and LRP4 Positive MG}

MuSK MG is a subgroup of the disease, accounting for less than $10 \%$ of all MG patients. The dominance of cranial, bulbar, and axial muscle involvement and the higher likelihood of early respiratory failure give rise to an aggressive picture that mandates consequent aggressive treatments. ${ }^{83}$ Some MuSK + MG patients do not respond to pyridostigmine. ${ }^{84}$ Standard doses of pyridostigmine frequently bring noticeable nicotinic side effects in these subjects, apparent both clinically (diffuse fasciculations and cramps) and at electrodiagnosis. ${ }^{21}$

Currently, based on pathological and clinical data, thymectomy is not recommended in anti-MuSK MG. ${ }^{85,86}$

Studies show that $\mathrm{MuSK}+\mathrm{MG}$ patients respond well to steroids and dramatically to PLEX. ${ }^{83}$ The great majority of patients (95 to $100 \%$ in different series) need immunosuppression therapy. ${ }^{87}$ In a study by Evoli et al on $57 \mathrm{MuSK}+$ patients, most patients (>90\%) needed immunosuppressive treatment, and 35 patients were treated with one or more courses of PLEX and IVIg. The complete remission rate was less than $10 \%$, and immunosuppressive treatment had been withdrawn in only less than $20 \%$ of the patients ${ }^{88}$ Rituximab may be a promising medication for Anti-MuSK + MG treatment. In a recent study on anti-MuSK + patients, $30 \%$ of the rituximab-treated MG patients used prednisone (mean dose $4.5 \mathrm{mg} /$ day) compared to $75 \%$ of the controls (mean dose $13 \mathrm{mg} / \mathrm{d}){ }^{89}$

LRP4, a receptor for agrin and an activator of MuSK, is expressed in the postsynaptic muscle membrane. ${ }^{90}$ LRP4 antibodies have been seen in $2-30 \%$ of the MG patients without AChR and MUSK antibodies (double seronegative), with a female dominance. Most of the patients manifest with ocular or generalized mild MG ( $20 \%$ of LRP 4 + patients with ocular MG), and respiratory insufficiency is infrequent in these cases. ${ }^{90}$ Usually, antiLRP4 patients have a mild phenotype, and their treatment mostly resembles AchR-Ab patients. ${ }^{90}$

\section{Recommendations}

- ChEIs can be used as the symptomatic treatment of patients with MuSK+MG; however, their efficacy may be less than AchR-Ab MGs with a greater chance of side effects and intolerability. Start AchEIs in MuSK patients at lower doses, and warn the patient of the possible side effects.

- For MuSK + MG patients with exacerbation or crisis, PLEX is preferred over IVIg.

- Most MuSK+MG patients required chronic corticosteroids treatment and have a favorable response to corticosteroids, but there is usually a recurrence of symptoms after tapering.

- Many MuSK+MG patients require immunosuppressives treatment as an add-on to corticosteroids: the immunosuppressive therapy of choice is rituximab. The exception is patients with mild symptoms and the subgroup that are effectively controlled by low dose corticosteroids.

\section{Thymoma and Myasthenia Gravis}

Thymoma is the most common mediastinal tumor among adults. This tumor mostly occurs between 50 and 65 years of age, and there is no meaningful difference between the two sexes. ${ }^{91}$ The occurrence of $M G$ in thymoma patients is about $50 \%$, and $15 \%$ of MG patients have thymoma. ${ }^{92}$ AchR autoantibody is almost always positive in thymoma patients ${ }^{93}$ supporting the notion that MG is a paraneoplastic manifestation of thymoma. ${ }^{93} \mathrm{MG}$ is more often related to WHO type B thymoma, ${ }^{94}$ and it does not usually occur in thymus carcinoma, which does not have a thymic epithelial origin..$^{95}$ Ryanodine receptor antibodies are present in $95 \%$ of thymomatous-MG patients and are associated with a more aggressive course. ${ }^{92}$ Respiratory symptoms are more prominent in Titin antibody-positive patients than other patients. ${ }^{96}$

Like non-myasthenic thymoma, thymectomy, 
radiotherapy, and chemotherapy are the mainstay of treatment in myasthenic patients. Radical resection is the standard treatment in most cases of thymoma. Different approaches, including median sternotomy and VATS, have been used for thymectomy in thymoma patients. Although current evidence comes from retrospective studies, VATS is considered a safe approach in skilled centers. In 2011, Zahid et al published a review of 74 papers on comparing VATS with median sternotomy. They concluded that VATS had superior results in the length of hospital stay, perioperative blood loss, and patient's satisfaction. ${ }^{97}$ In 2018, Ersen and colleagues reported no substantial difference in perioperative blood loss and surgery duration or pain between VATS and median sternotomy. However, the chest tube drainage period after surgery and hospitalization length were shorter in the VATS group. ${ }^{98}$

Radiotherapy \pm chemotherapy is also considered in stage 2 thymomas with a high risk of recurrence and stage 3 and 4 of the tumor when radical resection of thymoma is not possible..$^{99,100}$ In 2011, Romi published a review article on the management of thymoma in MG. They emphasized that other pharmacological treatments like acetylcholinesterase inhibitors, steroids, and steroidsparing drugs are used in thymoma MG, like nonthymoma, for controlling myasthenic symptoms. ${ }^{92}$

\section{Recommendations}

- All patients with thymoma, except stage $4 \mathrm{~b}$, who have diffuse metastasis, should undergo thymectomy regardless of MG status if there are no other contraindications.

- There is no significant difference between VATS and medial sternotomy, although because patients tolerate VATS better than open surgery, we recommend VATS, where there is enough expertise.

- Management of myasthenia symptoms and maintenance therapy do not vary between thymomatous and non-thymomatous MG patients. However, thymomatous MG patients have a more severe disease course and higher chance of relapse and probably more frequent and prolonged use of immunosuppressives.

- We suggest evaluating the recurrence of tumors in refractory patients or cases of relapse.

- Follow-up chest CT scan 6-12 months after surgery is recommended.

\section{MG in Elderly Patients (Late-Onset MG)}

In a large series of late-onset MG, $837 \mathrm{MG}$ patients were followed for 22 years, including 172 late-onset MG. ${ }^{101}$ In 67 patients treated with prednisone, improvement was observed in $76 \%$ patients and severe side effects in $18 \%$. In $46 \mathrm{MG}$ patients who received treatment with prednisone plus AZT, improvement was observed in $89 \%$ and severe side effects in $19.5 \%$. In seven late-onset MG patients treated with AZT alone, improvement was recorded in five with no side effects. ${ }^{101}$

\section{Recommendations}

- In late-onset, generalized AchR +MG (>65 years), start treatment with ChEIs plus AZT with or without prednisolone.

- Thymectomy is not recommended unless thymoma is suspected

\section{Pregnancy Issues in MG}

MG crisis or exacerbation occurs mainly in the $1^{\text {st }}$ trimester of pregnancy and postpartum period. ${ }^{102}$ Several studies have shown that pyridostigmine does not cross the placenta, and there have been no associations with fetal anomalies. The American Academy of Pediatrics considers pyridostigmine compatible with breastfeeding. ${ }^{103}$ However, intravenous AChEIs may produce uterine contractions and should not be used during pregnancy. ${ }^{104}$

Maintenance corticosteroids on the lowermost feasible dose can be maintained in pregnancy, ${ }^{103}$ and prednisolone is the preferred corticosteroid in pregnancy. ${ }^{104}$ Patients receiving more than $7.5 \mathrm{mg} / \mathrm{d}$ prednisolone for more than two weeks before delivery must obtain parenteral corticosteroids for stress dose. ${ }^{105}$ In contrast to prednisolone, methylprednisolone is accompanied by an increased risk of cleft palate once used in the $1^{\text {st }}$ trimester. ${ }^{105}$ Corticosteroids can be continued during breastfeeding. Some experts recommend discarding the breast milk for the first four hours after consumption of prednisolone dose more than $20 \mathrm{mg} \cdot{ }^{102}$

Regarding immunosuppressants, AZT has not been related to increased rates of congenital abnormalities. ${ }^{106}$ Therefore, it seems that AZT is harmless to administer during pregnancy and breastfeeding, but the drug dose should be below $100 \mathrm{mg} / \mathrm{d}$ when possible. ${ }^{107}$

Mycophenolate mofetil has had teratogenic effects in human studies. It is related to $1^{\text {st }}$ trimester abortion, and other structural anomalies. ${ }^{108}$

Methotrexate is contraindicated in pregnancy and breastfeeding. In women who plan for pregnancy and are using methotrexate, a wash-out period of at least three months should be considered before pregnancy. ${ }^{105}$

Cyclosporine and tacrolimus are not teratogenic. However, the risk of gestational diabetes mellitus and hypertension increases with tacrolimus use in pregnancy. ${ }^{109,110}$

IVIg and PLEX are considered to be safe in the treatment of acute myasthenic exacerbation during pregnancy. ${ }^{102}$

According to several studies, vaginal delivery is suggested for MG pregnant women. ${ }^{11}$ Cesarean section must be done only for obstetric indications. Some studies have suggested avoding general anesthesia and narcotics as they can synergistically potentiate AChR antibody effects. ${ }^{112}$

\section{Recommendations}

- Oral ChEIs are the first choice of treatment for MG during pregnancy, and they are safe.

- Prednisolone is safe during pregnancy as the first 
choice of immunomodulation drug with the lowest effective dose.

- Mycophenolate mofetil, cyclophosphamide, and methotrexate are contraindicated during pregnancy.

- If immunosuppressive therapy is necessary for pregnancy, AZT and cyclosporine are relatively safe agents that could be continued during pregnancy with the lowest effective dose.

- During a crisis, IVIg, or PLEX, could be used in pregnancy considering the mother and fetus's riskbenefit.

- Vaginal delivery is suggested for pregnant MG women as the first choice, and a Cesarean section must be carried out only for obstetric indications.

\section{Treatment of MG in COVID Era}

The fatality rate of the severe acute respiratory syndrome coronavirus 2 (SARS-CoV-2) in hospitalized adult patients is $2 \%-3 \%$. However, this rate can rise to $11 \%$ in the elderly and those with underlying comorbidities and immunocompromised states such as MG. ${ }^{113,114}$

Currently, there are limited data on how COVID-19 infects people with MG. Theoretically, there is a higher risk of suffering severe manifestations of COVID-19 owing to the frequent use of immunosuppressive drugs and potentially oropharyngeal and respiratory weakness. ${ }^{115,116}$

Therapy choices must be modified and made interactively between the patient with MG and physicians.

\section{Recommendations}

- MG patients must remain their treatment and are recommended not to stop any existing medications unless accepted by their physician.

- We recommend that MG patients even now on immunosuppressive treatments must practice face masking, extra-attentive social distancing, as well as avoiding public meetings and overcrowded public transportation. Also, frequent hand-washing and use of alcohol-based hand antiseptics should be considered.

- We recommend continuing symptomatic treatment with pyridostigmine as before.

- Although IVIg and plasmapheresis probably do not increase the risk of contracting the virus, reducing the frequency of infusions in stable patients and home infusions should be considered.

- In the case of corticosteroid use, consider the following: Prescribe the minimum required dose that prevents flare-ups, do not stop the drug abruptly, give the stress dose in the case of acute illness.

- For immunosuppressive drugs such as AZT, mycophenolate mofetil, cyclosporine, etc., it is recommended to continue treatment in patients on treatment with these drugs. If clinically plausible, delay the administration of new immunosuppressive until the epidemic is over.

- For B-cell depleting therapies such as rituximab, consider alternative treatments if deciding which IS to start, injections at longer intervals (especially if CD19 counts are lower than 0.5\%), or in smaller amounts.

\section{Transient Neonatal MG (TNMG)}

Ten to $30 \%$ of neonates born to mothers with MG develop TNMG. Infants with TNMG typically show weak cry, poor sucking, or ptosis 12 hours to four days after birth that continues from two weeks to several months afterwards. ${ }^{117}$ If the symptoms are transient and mild, no treatment is usually required. If symptoms are troublesome, pyridostigmine should be considered. ${ }^{118}$ One study recommended early treatment with PLEX once hydramnios or swallowing weakness in the newborn appear. ${ }^{119}$

\section{Recommendations}

- All infants with TNMG should be observed and examined for evidence of transient myasthenia weakness mainly through the first week and should have rapid access to neonatal critical care support (NICU).

- If symptoms are transient and mild, wait and observe or try pyridostigmine (Oral: $5 \mathrm{mg}$ each 4 to 6 hours IM, IV: 0.05 to $0.15 \mathrm{mg} / \mathrm{kg} /$ dose).

- In severe cases, start IVIg/PLEX and mechanical ventilation when necessary.

- Once hydramnios or weakened swallowing in the newborn appear, it is required to treat early with IVIg/PLEX.

- Corticosteroids and immunosuppressive are not indicated for TNMG.

\section{Vaccination}

Several placebo-controlled and retrospective studies have assessed the safety and efficacy of different vaccines in MG patients. Generally, inactivated vaccines are considered safe in MG patients. A prospective survey of tetanus revaccination showed a lower but significant immune response with no increased MG exacerbation risk. ${ }^{120}$ The humoral immune response to diphtheria and tetanus vaccinations was comparable with healthy controls in a retrospective investigation. ${ }^{121}$

Influenza vaccination has proven to be safe in retrospective studies, and the only randomized clinical trial of the Influenza vaccine in MG patients also approved its safety. ${ }^{122}$ Furthermore, it has been found that the risk of aggravating MG after an influenza-like illness was more than the risk associated with influenza vaccination, supporting routine influenza vaccination in MG patients. ${ }^{123}$ Live-attenuated vaccines must be avoided in MG patients on immunosuppressive treatment. Preferably, these vaccines should be considered 2 to 4 weeks before immunosuppressive therapy initiation ${ }^{124}$. In the case of rituximab planning, vaccination must be 
programmed before initiating the therapy or postponed to at least six months after the drug's latest cycle. ${ }^{124}$

\section{Recommendations}

- Inactivated vaccines can be used in the same way as the general population vaccination program.

- Live-attenuated vaccines must be avoided in MG patients on immunosuppressive therapy or planned to be used 2-4 weeks before immunosuppressive initiation.

- Vaccination must be programmed before initiating rituximab or postponed to at least six months after the drug's latest cycle.

\section{Drugs to Avoid in MG}

Different lists of drugs have been proposed to be contraindicated in MG according to case reports, in vitro studies, or retrospective data. ${ }^{125}$ Two categories of drugs seem to be more critical. The first is drugs and conditions known to induce autoimmune MG, including D-penicillamine, interferon-alpha and beta, etanercept, imiquimod, tandutinib, and immune checkpoint inhibitors. The other group is medications with black box warnings of FDA, namely botulinum toxin, ${ }^{125}$ fluoroquinolones (e.g., ciprofloxacin and levofloxacin), and telithromycin (i.e., Ketek). Other potentially aggravating drugs include ${ }^{125}$ : other antibiotics: aminoglycosides (such as gentamycin, neomycin), azithromycin, tetracyclines, sulfonamides, amino acid antibiotics (polymyxin B), nitrofurantoin, clindamycin and lincomycin, colistin, colistimethate; cardiovascular drugs, such as verapamil, procainamide, bretylium, quinidine, quinine, and oral magnesium; antiepileptic drugs, such as phenytoin and barbiturate; neuromuscular blocking agents and local anesthetics; eye drugs: timolol, betaxolol; psychiatric drugs: lithium; iodinated contrast. ${ }^{126}$

\section{Recommendations}

- Drugs that induce MG, those with black box warnings including injectable magnesium, immune checkpoint inhibitors, and botulinum toxin, should be avoided in MG patients unless in life-threatening conditions when no alternative exists.

- Other drugs that need particular caution include: fluoroquinolones(e.g., ciprofloxacinandlevofloxacin), telithromycin (i.e., Ketek), aminoglycosides (such as gentamycin, neomycin), azithromycin, tetracyclines, sulfonamides, amino acid antibiotics (polymyxin B), nitrofurantoin, clindamycin, and lincomycin, colistin, verapamil, procainamide, bretylium, quinidine, quinine, oral magnesium, phenytoin and barbiturate, neuromuscular blocking agents and local anesthetics, eye drop (timolol, betaxolol), lithium, iodinated contrast

- Regarding other drugs that can potentially worsen MG, clinical judgment is necessary not to deprive patients of receiving appropriate treatments.

\section{Perioperative Considerations}

Two retrospective studies have been conducted on MG patients preoperatively. One has compared routine preoperative PLEX with selective PLEX of severe cases. ${ }^{127}$ The other has evaluated PLEX versus no additional treatment in stable patients. ${ }^{128}$ None showed a significant change between the two groups. There is no international or regional consensus for perioperative management of MG patients to date. The only related studies are those evaluating the likelihood of a postsurgical myasthenic crisis. In one study, it was found that patients with a duration of disease more than six years, preceding respiratory complaints, pyridostigmine doses more than $750 \mathrm{mg} / \mathrm{d}$, and forced vital capacity less than 2.9 L preoperatively were associated with postoperative respiratory failure. ${ }^{129-131}$

\section{Recommendations}

- Routine PLEX/IVIg is not indicated in all MG patients preoperatively. PLEX is preferred in MG patients with moderate to severe manifestations before surgery due to its faster onset of action.

- Pay special attention to the severity of the disease, mainly respiratory function and bulbar symptoms.

- The best time to perform an elective surgery is when the patient is in stable conditions.

- In emergency surgeries, plasmapheresis should be considered in an MG patient with moderate to severe manifestations.

- $\quad$ Steroid stress dose is similar to other patients taking chronic corticosteroids.

- Routine pre-treatment with sedative or opioid medications should be prohibited as they increase the risk of respiratory depression.

- Depolarizing neuromuscular blocking agents are preferred over non-depolarizing drugs. If nondepolarizing agents must be used, short- and intermediate-acting agents are prioritized.

- Although there is a theoretical increase in the risk of vagal responses and the dose of non-depolarizing neuromuscular blocking agents by AChEIs, it is recommended to keep the same dose of AChEIs in stable MG patients perioperatively.

- Although AZT and corticosteroids may interfere with some anesthetic drugs, theoretically, there is no need to change the dose of corticosteroids and immunosuppressives in a stable patient.

In conclusion, in this guideline, we attempted to develop a guideline based on Iran's local requirements. We hope that these guidelines help healthcare professionals with proper treatment and follow-up of patients with MG.

\section{Authors' Contribution}

$\mathrm{SN}$ and FF organized the panel sessions. FF, AAO, FS, BA, HA, $\mathrm{KB}, \mathrm{RB}, \mathrm{BHA}, \mathrm{PS}$, and $\mathrm{SN}$ contributed to consensus preparation, including literature review and writing the initial draft for each section, and also the final manuscript. All authors have read and approved the final manuscript. 


\section{Conflict of Interest Disclosures}

The authors declare that the research was conducted in the absence of any commercial or financial relationships that could be construed as a potential conflict of interest.

\section{Ethical Statement}

The study was conducted as per the ethical principles of the Helsinki Declaration.

\section{Funding}

The authors have not declared a specific grant for this research from any funding agency in the public, commercial or not-for-profit sectors.

\section{References}

1. Ciafaloni E. Myasthenia gravis and congenital myasthenic syndromes. Continuum (Minneap Minn). 2019;25(6):176784. doi: 10.1212/con.0000000000000800.

2. Farmakidis C, Pasnoor M, Dimachkie MM, Barohn RJ. Treatment of myasthenia gravis. Neurol Clin. 2018;36(2):31137. doi: 10.1016/j.ncl.2018.01.011.

3. Sanders DB, Wolfe Gl, Benatar M, Evoli A, Gilhus NE, Illa $\mathrm{I}$, et al. International consensus guidance for management of myasthenia gravis: Executive summary. Neurology. 2016;87(4):419-25. doi: 10.1212/wnl.0000000000002790.

4. Anderson D, Phan C, Johnston WS, Siddiqi ZA. Rituximab in refractory myasthenia gravis: a prospective, open-label study with long-term follow-up. Ann Clin Transl Neurol. 2016;3(7):552-5. doi: 10.1002/acn3.314.

5. Beecher G, Anderson D, Siddiqi ZA. Rituximab in refractory myasthenia gravis: Extended prospective study results. Muscle Nerve. 2018;58(3):452-5. doi: 10.1002/mus.26156.

6. Marino M, Basile U, Spagni G, Napodano C, lorio R, Gulli $\mathrm{F}$, et al. Long-lasting rituximab-induced reduction of specificbut not total-lgG4 in MuSK-positive myasthenia gravis. Front Immunol. 2020;11:613. doi: 10.3389/fimmu.2020.00613.

7. Howard JF Jr. Electrodiagnosis of disorders of neuromuscular transmission. Phys Med Rehabil Clin N Am. 2013;24(1):16992. doi: 10.1016/j.pmr.2012.08.013.

8. Sanders DB. Clinical impact of single-fiber electromyography. Muscle Nerve Suppl. 2002;11:S15-20. doi: 10.1002/ mus.10141.

9. Keesey JC. Clinical evaluation and management of myasthenia gravis. Muscle Nerve. 2004;29(4):484-505. doi: 10.1002/ mus.20030.

10. Evoli A, Padua L. Diagnosis and therapy of myasthenia gravis with antibodies to muscle-specific kinase. Autoimmun Rev. 2013;12(9):931-5. doi: 10.1016/j.autrev.2013.03.004.

11. Oh SJ, Cho HK. Edrophonium responsiveness not necessarily diagnostic of myasthenia gravis. Muscle Nerve. 1990;13(3):187-91. doi: 10.1002/mus.880130302.

12. Benatar M. A systematic review of diagnostic studies in myasthenia gravis. Neuromuscul Disord. 2006;16(7):459-67. doi: 10.1016/j.nmd.2006.05.006.

13. Mehanna R, Patton EL Jr, Phan CL, Harati Y. Amyotrophic lateral sclerosis with positive anti-acetylcholine receptor antibodies. Case report and review of the literature. J Clin Neuromuscul Dis. 2012;14(2):82-5. doi: 10.1097/ CND.0b013e31824db163.

14. Andreetta F, Rinaldi E, Bartoccioni E, Riviera AP, Bazzigaluppi E, Fazio $R$, et al. Diagnostics of myasthenic syndromes: detection of anti-AChR and anti-MuSK antibodies. Neurol Sci. 2017;38(Suppl 2):253-7. doi: 10.1007/s10072-017-3026-2.

15. Zisimopoulou P, Evangelakou P, Tzartos J, Lazaridis K, Zouvelou V, Mantegazza R, et al. A comprehensive analysis of the epidemiology and clinical characteristics of anti-LRP4 in myasthenia gravis. J Autoimmun. 2014;52:139-45. doi: 10.1016/j.jaut.2013.12.004.

16. Evoli A, Antonini G, Antozzi C, DiMuzio A, Habetswallner F, Iani $\mathrm{C}$, et al. Italian recommendations for the diagnosis and treatment of myasthenia gravis. Neurol Sci. 2019;40(6):111124. doi: 10.1007/s10072-019-03746-1.

17. Mehndiratta MM, Pandey S, Kuntzer T. Acetylcholinesterase inhibitor treatment for myasthenia gravis. Cochrane Database Syst Rev. 2014;2014(10):CD006986. doi: 10.1002/14651858. CD006986.pub3.

18. Ricciardi R, Rossi B, Nicora M, Sghirlanzoni A, Muratorio A. Acute treatment of myasthenia gravis with intranasal neostigmine: clinical and electromyographic evaluation. J Neurol Neurosurg Psychiatry. 1991;54(12):1061-2. doi: 10.1136/jnnp.54.12.1061.

19. Ionita CM, Acsadi G. Management of juvenile myasthenia gravis. Pediatr Neurol. 2013;48(2):95-104. doi: 10.1016/j. pediatrneurol.2012.07.008.

20. Chiang LM, Darras BT, Kang PB. Juvenile myasthenia gravis. Muscle Nerve. 2009;39(4):423-31. doi: 10.1002/mus.21195.

21. Oh SJ. Muscle-specific receptor tyrosine kinase antibody positive myasthenia gravis current status. J Clin Neurol. 2009;5(2):53-64. doi: 10.3988/jcn.2009.5.2.53.

22. Gajdos P, Chevret S, Toyka K. Intravenous immunoglobulin for myasthenia gravis. Cochrane Database Syst Rev. 2006(2):CD002277. doi: 10.1002/14651858.CD002277. pub2.

23. Jongen JL, van Doorn PA, van der Meché FG. High-dose intravenous immunoglobulin therapy for myasthenia gravis. J Neurol. 1998;245(1):26-31. doi: 10.1007/s004150050170.

24. Ferrero B, Durelli L. High-dose intravenous immunoglobulin G treatment of myasthenia gravis. Neurol Sci. 2002;23 Suppl 1:S9-24. doi: 10.1007/s100720200011.

25. Wegner B, Ahmed I. Intravenous immunoglobulin monotherapy in long-term treatment of myasthenia gravis. Clin Neurol Neurosurg. 2002;105(1):3-8. doi: 10.1016/ s0303-8467(02)00017-3.

26. Gajdos P, Chevret S, Toyka K. Intravenous immunoglobulin for myasthenia gravis. Cochrane Database Syst Rev. 2003(2):CD002277. doi: 10.1002/14651858.cd002277.

27. Arsura EL, Bick A, Brunner NG, Namba T, Grob D. Highdose intravenous immunoglobulin in the management of myasthenia gravis. Arch Intern Med. 1986;146(7):1365-8. doi: 10.1001/archinte.1986.00360190143020.

28. Bonaventura I, Ponseti J, Arnau E, Matias-GuiuJ, Codina Puiggros A. High-dose intravenous immunoglobulin in the management of myasthenia gravis. Arch Intern Med. 1987;147(2):207-11. doi: 10.1001/archinte.1987.00370020027019.

29. Evoli A, Palmisani MT, Bartoccioni E, Padua L, Tonali P. Highdose intravenous immunoglobulin in myasthenia gravis. Ital J Neurol Sci. 1993;14(3):233-7. doi: 10.1007/bf02335664.

30. Kumar R, Birinder SP, Gupta S, Singh G, Kaur A. Therapeutic plasma exchange in the treatment of myasthenia gravis. Indian J Crit Care Med. 2015;19(1):9-13. doi: 10.4103/09725229.148631.

31. Taiuti R, Avanzi G, Paoletti P, Marconi G. Plasma-exchange in myasthenia gravis: a study in 20 patients. Int J Artif Organs. 1988;11(4):308-12.

32. Fornádi L, Horváth R, Szobor A. Myasthenia gravis: treatment with plasma exchange experiences over 10 years. Acta Med Hung. 1991;48(3-4):137-44.

33. Kuks JB, Das PC. Plasma exchange in myasthenia gravis. Int J Artif Organs. 1998;21(4):188-91.

34. Gajdos P, Chevret S, Toyka K. Plasma exchange for myasthenia gravis. Cochrane Database Syst Rev. 2002(4):CD002275. doi: 10.1002/14651858.cd002275.

35. Durelli L, Cocito D, Bergamini L. Rapid improvement of myasthenia gravis after plasma exchange? Ann Neurol. 1983;13(2):220-1. doi: 10.1002/ana.410130231. 
36. d'Empaire G, Hoaglin DC, Perlo VP, Pontoppidan H. Effect of prethymectomy plasma exchange on postoperative respiratory function in myasthenia gravis. J Thorac Cardiovasc Surg. 1985;89(4):592-6.

37. Thorlacius S, Aarli JA, Jacobsen H, Halvorsen K. Plasma exchange in myasthenia gravis: clinical effect. Acta Neurol Scand. 1985;72(5):464-8. doi: 10.1111/j.1600-0404.1985. tb00902.x.

38. Keesey J, Buffkin D, Kebo D, Ho W, Herrmann C, Jr. Plasma exchange alone as therapy for myasthenia gravis. Ann N Y Acad Sci. 1981;377:729-43. doi: 10.1111/j.1749-6632.1981. tb33771.x.

39. Estournet B. Plasma exchange in the treatment of myasthenia gravis. Intensive Care Med. 1979;5(4):203. doi: 10.1007/ bf01683938.

40. Newsom-Davis J, Vincent A. Combined plasma exchange and immunosuppression in myasthenia gravis. Lancet. 1979;2(8144):688. doi: 10.1016/s0140-6736(79)92081-6.

41. Behan PO, Shakir RA, Simpson JA, Burnett AK, Allan TL, Haase G. Plasma-exchange combined with immunosuppressive therapy in myasthenia gravis. Lancet. 1979;2(8140):438-40. doi: 10.1016/s0140-6736(79)91492-2.

42. Pinching AJ, Peters DK, Davis JN. Plasma exchange in myasthenia gravis. Lancet. 1977;1(8008):428-9. doi: 10.1016/ s0140-6736(77)92639-3.

43. Finn R, Coates PM. Plasma exchange in myasthenia gravis. Lancet. 1977;1(8004):190-1. doi: 10.1016/s01406736(77)91782-2.

44. Hilkevich O, Drory VE, Chapman J, Korczyn AD. The use of intravenous immunoglobulin as maintenance therapy in myasthenia gravis. Clin Neuropharmacol. 2001;24(3):173-6. doi: 10.1097/00002826-200105000-00010.

45. Huang CS, Hsu HS, Kao KP, Huang MH, Huang BS. Intravenous immunoglobulin in the preparation of thymectomy for myasthenia gravis. Acta Neurol Scand. 2003;108(2):136-8. doi: 10.1034/j.1600-0404.2003.00131.x.

46. Ortiz-Salas P, Velez-Van-Meerbeke A, Galvis-Gomez CA, Rodriguez QJ. Human immunoglobulin versus plasmapheresis in Guillain-Barre syndrome and myasthenia gravis: a metaanalysis. J Clin Neuromuscul Dis. 2016;18(1):1-11. doi: 10.1097/cnd.0000000000000119.

47. Gajdos P, Chevret S, Clair B, Tranchant C, Chastang C. Clinical trial of plasma exchange and high-dose intravenous immunoglobulin in myasthenia gravis. Myasthenia Gravis Clinical Study Group. Ann Neurol. 1997;41(6):789-96. doi: 10.1002/ana.410410615.

48. Qureshi Al, Choudhry MA, Akbar MS, Mohammad Y, Chua $\mathrm{HC}$, Yahia AM, et al. Plasma exchange versus intravenous immunoglobulin treatment in myasthenic crisis. Neurology. 1999;52(3):629-32. doi: 10.1212/wnl.52.3.629.

49. Barth D, Nabavi Nouri M, Ng E, Nwe P, Bril V. Comparison of IVIg and PLEX in patients with myasthenia gravis. Neurology. 2011;76(23):2017-23. doi: 10.1212/ WNL.0b013e31821e5505.

50. Sonett JR, Jaretzki A, 3rd. Thymectomy for nonthymomatous myasthenia gravis: a critical analysis. Ann N Y Acad Sci. 2008;1132:315-28. doi: 10.1196/annals.1405.004.

51. Gronseth GS, Barohn RJ. Practice parameter: thymectomy for autoimmune myasthenia gravis (an evidence-based review): report of the Quality Standards Subcommittee of the American Academy of Neurology. Neurology. 2000;55(1):7-15. doi: 10.1212/wnl.55.1.7.

52. Cea G, Benatar M, Verdugo RJ, Salinas RA. Thymectomy for non-thymomatous myasthenia gravis. Cochrane Database Syst Rev. 2013(10):CD008111. doi: 10.1002/14651858. CD008111.pub2.

53. Wolfe Gl, Kaminski HJ, Aban IB, Minisman G, Kuo HC, Marx $\mathrm{A}$, et al. Randomized trial of thymectomy in myasthenia gravis. N Engl J Med. 2016;375(6):511-22. doi: 10.1056/ NEJMoa1602489.

54. Wolfe Gl, Kaminski HJ, Aban IB, Minisman G, Kuo HC, Marx A, et al. Long-term effect of thymectomy plus prednisone versus prednisone alone in patients with non-thymomatous myasthenia gravis: 2-year extension of the MGTX randomised trial. Lancet Neurol. 2019;18(3):259-68. doi: 10.1016/s14744422(18)30392-2.

55. Benveniste MF, Rosado-de-Christenson ML, Sabloff BS, Moran CA, Swisher SG, Marom EM. Role of imaging in the diagnosis, staging, and treatment of thymoma. Radiographics. 2011;31(7):1847-61; discussion 61-3. doi: 10.1148/ rg.317115505.

56. Jaretzki A, Steinglass KM, Sonett JR. Thymectomy in the management of myasthenia gravis. Semin Neurol. 2004;24(1):49-62. doi: 10.1055/s-2004-829596.

57. Skeie GO, Apostolski S, Evoli A, Gilhus NE, Illa I, Harms L, et al. Guidelines for treatment of autoimmune neuromuscular transmission disorders. Eur J Neurol. 2010;17(7):893-902. doi: 10.1111/j.1468-1331.2010.03019.x.

58. Kumar V, Kaminski HJ. Treatment of myasthenia gravis. Curr Neurol Neurosci Rep. 2011;11(1):89-96. doi: 10.1007/ s11910-010-0151-1.

59. Seyfari B, Fatehi F, Shojaiefard A, Jafari M, GhorbaniAbdehgah A, Nasiri S, et al. Clinical outcome of thymectomy in myasthenia gravis patients: A report from Iran. Iran J Neurol. 2018;17(1):1-5.

60. Yablonsky P, Pischik V, Tovbina MG, Atiukov M. The results of video-assisted thoracoscopic thymectomies in Saint Petersburg, Russia: 20-year of experience. J Vis Surg. 2017;3:113. doi: 10.21037/jovs.2017.06.13.

61. Meyer DM, Herbert MA, Sobhani NC, Tavakolian P, Duncan A, Bruns $M$, et al. Comparative clinical outcomes of thymectomy for myasthenia gravis performed by extended transsternal and minimally invasive approaches. Ann Thorac Surg. 2009;87(2):385-90. doi: 10.1016/j.athoracsur.2008.11.040.

62. Kim JY, Park KD, Richman DP. Treatment of myasthenia gravis based on its immunopathogenesis. J Clin Neurol. 2011;7(4):173-83. doi: 10.3988/jcn.2011.7.4.173.

63. Arsura E, Brunner NG, Namba T, Grob D. High-dose intravenous methylprednisolone in myasthenia gravis. Arch Neurol. 1985;42(12):1149-53. doi: 10.1001/ archneur.1985.04060110031011.

64. Palace J, Newsom-Davis J, Lecky B. A randomized doubleblind trial of prednisolone alone or with azathioprine in myasthenia gravis. Myasthenia Gravis Study Group. Neurology. 1998;50(6):1778-83. doi: 10.1212/wnl.50.6.1778.

65. Muscle Study Group. A trial of mycophenolate mofetil with prednisone as initial immunotherapy in myasthenia gravis. Neurology. 2008;71(6):394-9. doi: 10.1212/01. wnl.0000312373.67493.7f

66. Sanders DB, Hart IK, Mantegazza R, Shukla SS, Siddiqi ZA, De Baets $\mathrm{MH}$, et al. An international, phase III, randomized trial of mycophenolate mofetil in myasthenia gravis. Neurology. 2008;71(6):400-6. doi: 10.1212/01.wnl.0000312374.95186. CC.

67. Pasnoor M, He J, Herbelin L, Burns TM, Nations S, Bril V, et al A randomized controlled trial of methotrexate for patients with generalized myasthenia gravis. Neurology. 2016;87(1):57-64. doi: 10.1212/wnl.0000000000002795.

68. Zhou L, Liu W, Li W, Li H, Zhang X, Shang H, et al. Tacrolimus in the treatment of myasthenia gravis in patients with an inadequate response to glucocorticoid therapy: randomized, double-blind, placebo-controlled study conducted in China. Ther Adv Neurol Disord. 2017;10(9):315-25. doi: 10.1177/1756285617721092.

69. De Feo LG, Schottlender J, Martelli NA, Molfino NA. Use of intravenous pulsed cyclophosphamide in severe, generalized 
myasthenia gravis. Muscle Nerve. 2002;26(1):31-6. doi: 10.1002/mus.10133.

70. Tindall RS, Phillips JT, Rollins JA, Wells L, Hall K. A clinical therapeutic trial of cyclosporine in myasthenia gravis. Ann NY Acad Sci. 1993;681:539-51. doi: 10.1111/j.1749-6632.1993. tb22937.x.

71. Tindall RS, Rollins JA, Phillips JT, Greenlee RG, Wells L, Belendiuk G. Preliminary results of a double-blind, randomized, placebo-controlled trial of cyclosporine in myasthenia gravis. N Engl J Med. 1987;316(12):719-24. doi: 10.1056/nejm198703193161205.

72. Tandan R, Hehir MK 2nd, Waheed W, Howard DB. Rituximab treatment of myasthenia gravis: A systematic review. Muscle Nerve. 2017;56(2):185-196. doi: 10.1002/mus.25597.

73. Dos Santos A, Noury JB, Genestet S, Nadaj-Pakleza A, Cassereau J, Baron C, et al. Efficacy and safety of rituximab in myasthenia gravis: a French multicentre real-life study. Eur J Neurol. 2020;27(11):2277-85. doi: 10.1111/ene.14391.

74. Turner B, Cree BAC, Kappos L, Montalban X, Papeix C, Wolinsky JS, et al. Ocrelizumab efficacy in subgroups of patients with relapsing multiple sclerosis. J Neurol. 2019;266(5):1182-93. doi: 10.1007/s00415-019-09248-6.

75. Howard JF Jr, Utsugisawa K, Benatar M, Murai H, Barohn RJ, Illa I, et al. Safety and efficacy of eculizumab in antiacetylcholine receptor antibody-positive refractory generalised myasthenia gravis (REGAIN): a phase 3, randomised, doubleblind, placebo-controlled, multicentre study. Lancet Neurol. 2017;16(12):976-86. doi: 10.1016/s1474-4422(17)30369-1.

76. McKeage K. Ravulizumab: first global approval. Drugs. 2019;79(3):347-52. doi: 10.1007/s40265-019-01068-2.

77. Howard JF Jr, Nowak RJ, Wolfe GI, Freimer ML, Vu TH, Hinton $J \mathrm{~L}$, et al. Clinical effects of the self-administered subcutaneous complement inhibitor zilucoplan in patients with moderate to severe generalized myasthenia gravis: results of a phase 2 randomized, double-blind, placebo-controlled, multicenter clinical trial. JAMA Neurol. 2020;77(5):582-92. doi: 10.1001/ jamaneurol.2019.5125.

78. Howard JF Jr, Bril V, Burns TM, Mantegazza R, Bilinska M, Szczudlik A, et al. Randomized phase 2 study of FCRn antagonist efgartigimod in generalized myasthenia gravis. Neurology. 2019;92(23):e2661-e73. doi: 10.1212/ wnl.0000000000007600.

79. Cartwright SL, Cartwright MS. Health maintenance for adults with neuromuscular diseases on immunosuppression. Muscle Nerve. 2019;59(4):397-403. doi: 10.1002/mus.26382.

80. Kerty E, Elsais A, Argov Z, Evoli A, Gilhus NE. EFNS/ENS Guidelines for the treatment of ocular myasthenia. Eur J Neurol. 2014;21(5):687-93. doi: 10.1111/ene.12359.

81. Wong SH, Huda S, Vincent A, Plant GT. Ocular myasthenia gravis: controversies and updates. Curr Neurol Neurosci Rep. 2014;14(1):421. doi: 10.1007/s11910-013-0421-9.

82. Benatar M, McDermott MP, Sanders DB, Wolfe Gl, Barohn RJ, Nowak RJ, et al. Efficacy of prednisone for the treatment of ocular myasthenia (EPITOME): a randomized, controlled trial. Muscle Nerve. 2016;53(3):363-9. doi: 10.1002/mus.24769.

83. Evoli A, Padua L. Diagnosis and therapy of myasthenia gravis with antibodies to muscle-specific kinase. Autoimmun Rev. 2013;12(9):931-5. doi: 10.1016/j.autrev.2013.03.004.

84. Evoli A, Tonali PA, Padua L, Monaco ML, Scuderi F, Batocchi $\mathrm{AP}$, et al. Clinical correlates with anti-MuSK antibodies in generalized seronegative myasthenia gravis. Brain. 2003;126(Pt 10):2304-11. doi: 10.1093/brain/awg223.

85. Lauriola L, Ranelletti F, Maggiano N, Guerriero M, Punzi C, Marsili F, et al. Thymus changes in anti-MuSK-positive and -negative myasthenia gravis. Neurology. 2005;64(3):536-8. doi: 10.1212/01.wnl.0000150587.71497.b6.

86. Leite MI, Ströbel P, Jones M, Micklem K, Moritz R, Gold R, et al. Fewer thymic changes in MuSK antibody-positive than in
MuSK antibody-negative MG. Ann Neurol. 2005;57(3):444-8. doi: 10.1002/ana.20386.

87. Oh SJ. Muscle-specific receptor tyrosine kinase antibody positive myasthenia gravis current status. J Clin Neurol. 2009;5(2):53-64. doi: 10.3988/jcn.2009.5.2.53.

88. Evoli A, Bianchi MR, Riso R, Minicuci GM, Batocchi AP, Servidei $S$, et al. Response to therapy in myasthenia gravis with anti-MuSK antibodies. Ann N Y Acad Sci. 2008;1132:76-83. doi: 10.1196/annals.1405.012.

89. Hehir MK, Hobson-Webb LD, Benatar M, Barnett C, Silvestri NJ, Howard JF Jr, et al. Rituximab as treatment for antiMuSK myasthenia gravis: multicenter blinded prospective review. Neurology. 2017;89(10):1069-77. doi: 10.1212/ wnl.0000000000004341.

90. Higuchi O, Hamuro J, Motomura M, Yamanashi Y. Autoantibodies to low-density lipoprotein receptor-related protein 4 in myasthenia gravis. Ann Neurol. 2011;69(2):41822. doi: 10.1002/ana.22312.

91. Kaminski HJ. Myasthenia Gravis and Related Disorders. Totowa, NJ: Humana Press; 2009.

92. Romi F. Thymoma in myasthenia gravis: from diagnosis to treatment. Autoimmune Dis. 2011;2011:474512. doi: 10.4061/2011/474512.

93. Romi F, Skeie GO, Aarli JA, Gilhus NE. Muscle autoantibodies in subgroups of myasthenia gravis patients. J Neurol. 2000;247(5):369-75. doi: 10.1007/s004150050604.

94. Cheney RT. The biologic spectrum of thymic epithelial neoplasms: current status and future prospects. J Natl Compr Canc Netw. 2010;8(11):1322-8. doi: 10.6004/ jnccn.2010.0097.

95. Kumar R. Myasthenia gravis and thymic neoplasms: a brief review. World J Clin Cases. 2015;3(12):980-3. doi: 10.12998/ wjcc.v3.i12.980.

96. Romi F, Aarli JA, Gilhus NE. Myasthenia gravis patients with ryanodine receptor antibodies have distinctive clinical features. Eur J Neurol. 2007;14(6):617-20. doi: 10.1111/j.14681331.2007.01785.x

97. Zahid I, Sharif S, Routledge T, Scarci M. Video-assisted thoracoscopic surgery or transsternal thymectomy in the treatment of myasthenia gravis? Interact Cardiovasc Thorac Surg. 2011;12(1):40-6. doi: 10.1510/icvts.2010.251041.

98. Erşen E, Kılıç B, Kara HV, İşcan M, Sarbay İ, Demirkaya A, et al. Comparative study of video-assisted thoracoscopic surgery versus open thymectomy for thymoma and myasthenia gravis. Wideochir Inne Tech Maloinwazyjne. 2018;13(3):376-82. doi: 10.5114/wiitm.2018.75835.

99. Fujii Y. Published guidelines for management of thymoma. Thorac Surg Clin. 2011;21(1):125-9. doi: 10.1016/j. thorsurg.2010.08.002.

100. Falkson CB, Bezjak A, Darling G, Gregg R, Malthaner R, Maziak DE, et al. The management of thymoma: a systematic review and practice guideline. J Thorac Oncol. 2009;4(7):9119. doi: 10.1097/jto.0b013e3181a4b8e0.

101. Evoli A, Batocchi AP, Minisci C, Di Schino C, Tonali P. Clinical characteristics and prognosis of myasthenia gravis in older people. J Am Geriatr Soc. 2000;48(11):1442-8. doi: 10.1111/ j.1532-5415.2000.tb02635.x.

102. Shimizu Y, Kitagawa K. Management of myasthenia gravis in pregnancy. Clin Exp Neuroimmunol. 2016;7(2):199-204. doi: 10.1111/cen3.12305.

103. Freyer AM. Drugs in pregnancy and lactation 8th edition: a reference guide to fetal and neonatal risk. Obstet Med. 2009;2(2):89. doi: 10.1258/om.2009.090002.

104. Stafford IP, Dildy GA. Myasthenia gravis and pregnancy. Clin Obstet Gynecol. 2005;48(1):48-56. doi: 10.1097/01. grf.0000153206.85996.07.

105. Norwood F, Dhanjal M, Hill M, James N, Jungbluth H, Kyle $\mathrm{P}$, et al. Myasthenia in pregnancy: best practice guidelines 
from a U.K. multispecialty working group. J Neurol Neurosurg Psychiatry. 2014;85(5):538-43. doi: 10.1136/jnnp-2013305572.

106. Ostensen M, Brucato A, Carp H, Chambers C, Dolhain RJ, Doria $\mathrm{A}$, et al. Pregnancy and reproduction in autoimmune rheumatic diseases. Rheumatology (Oxford). 2011;50(4):65764. doi: 10.1093/rheumatology/keq350.

107. Sau A, Clarke S, Bass J, Kaiser A, Marinaki A, NelsonPiercy C. Azathioprine and breastfeeding: is it safe? Bjog. 2007;114(4):498-501. doi: 10.1111/j.14710528.2006.01232.x.

108. Sifontis NM, Coscia LA, Constantinescu S, Lavelanet AF, Moritz MJ, Armenti VT. Pregnancy outcomes in solid organ transplant recipients with exposure to mycophenolate mofetil or sirolimus. Transplantation. 2006;82(12):1698-702. doi: 10.1097/01.tp.0000252683.74584.29.

109. Bar Oz B, Hackman R, Einarson T, Koren G. Pregnancy outcome after cyclosporine therapy during pregnancy: a meta-analysis. Transplantation. 2001;71(8):1051-5. doi: 10.1097/00007890-200104270-00006.

110. Kainz A, Harabacz I, Cowlrick IS, Gadgil SD, Hagiwara D. Review of the course and outcome of 100 pregnancies in 84 women treated with tacrolimus. Transplantation. 2000;70(12):1718-21. doi: 10.1097/00007890-20001227000010.

111. Ferrero S, Pretta S, Nicoletti A, Petrera P, Ragni N. Myasthenia gravis: management issues during pregnancy. Eur J Obstet Gynecol Reprod Biol. 2005;121(2):129-38. doi: 10.1016/j. ejogrb.2005.01.002.

112. Varner M. Myasthenia gravis and pregnancy. Clin Obstet Gynecol. 2013;56(2):372-81. doi: 10.1097/ GRF.0b013e31828e92c0.

113. Jacob S, Muppidi S, Guidon A, Guptill J, Hehir M, Howard JF $J r$, et al. Guidance for the management of myasthenia gravis (MG) and Lambert-Eaton myasthenic syndrome (LEMS) during the COVID-19 pandemic. J Neurol Sci. 2020;412:116803. doi: 10.1016/j.jns.2020.116803.

114. Hübers A, Lascano AM, Lalive PH. Management of patients with generalised myasthenia gravis and COVID-19: four case reports. J Neurol Neurosurg Psychiatry. 2020;91(10):1124-5. doi: 10.1136/jnnp-2020-323565.

115. Aksoy E, Oztutgan T. COVID-19 presentation in association with myasthenia gravis: a case report and review of the literature. Case Rep Infect Dis. 2020;2020:8845844. doi: 10.1155/2020/8845844.

116. Costamagna G, Abati E, Bresolin N, Comi GP, Corti S. Management of patients with neuromuscular disorders at the time of the SARS-CoV-2 pandemic. J Neurol. 2021;268(5):1580-91. doi: 10.1007/s00415-020-10149-2.

117. Hoff JM, Daltveit AK, Gilhus NE. Myasthenia gravis in pregnancy and birth: identifying risk factors, optimising care. Eur J Neurol. 2007;14(1):38-43. doi: 10.1111/j.14681331.2006.01538.x.

118. Béhin A, Mayer M, Kassis-Makhoul B, Jugie M, Espil-Taris C, Ferrer $\mathrm{X}$, et al. Severe neonatal myasthenia due to maternal
anti-MuSK antibodies. Neuromuscul Disord. 2008;18(6):4436. doi: 10.1016/j.nmd.2008.03.006.

119. Kanzaki A, Motomura M. [A pregnant patient with anti-MuSK antibody positive myasthenia gravis and her infant with transient neonatal myasthenia gravis]. Rinsho Shinkeigaku. 2011;51(3):188-91. doi: 10.5692/clinicalneurol.51.188. [Japanese].

120. Strijbos E, Huijbers MG, van Es IE, Alleman I, van OstaijenTen Dam MM, Bakker J, et al. A prospective, placebo controlled study on the humoral immune response to and safety of tetanus revaccination in myasthenia gravis. Vaccine. 2017;35(46):6290-6. doi: 10.1016/j.vaccine.2017.09.078.

121. Csuka D, Czirják L, Hóbor R, Illes Z, Bánáti M, Rajczy K, et al. Effective humoral immunity against diphtheria and tetanus in patients with systemic lupus erythematosus or myasthenia gravis. Mol Immunol. 2013;54(3-4):453-6. doi: 10.1016/j. molimm.2013.01.012.

122. Tackenberg B, Schneider M, Blaes F, Eienbröker C, SchadeBrittinger C, Wellek A, et al. Acetylcholine receptor antibody titers and clinical course after influenza vaccination in patients with myasthenia gravis: a double-blind randomized controlled trial (ProPATlent-Trial). EBioMedicine. 2018;28:143-50. doi: 10.1016/j.ebiom.2018.01.007.

123. Seok HY, Shin HY, Kim JK, Kim BJ, Oh J, Suh BC, et al. The impacts of influenza infection and vaccination on exacerbation of myasthenia gravis. J Clin Neurol. 2017;13(4):325-30. doi: 10.3988/jcn.2017.13.4.325.

124. Gilhus NE, Romi F, Hong Y, Skeie GO. Myasthenia gravis and infectious disease. J Neurol. 2018;265(6):1251-8. doi: 10.1007/s00415-018-8751-9.

125. Mehrizi M, Fontem RF, GearhartTR, Pascuzzi RM. Medications and Myasthenia Gravis (A Reference for Health Care Professionals). Myasthenia Gravis Foundation of America; 2012. p. 1-49.

126. Rath J, Mauritz M, Zulehner G, Hilger E, Cetin H, Kasprian G, et al. lodinated contrast agents in patients with myasthenia gravis: a retrospective cohort study. J Neurol. 2017;264(6):1209-17. doi: 10.1007/s00415-017-8518-8.

127. El-Bawab H, Hajjar W, Rafay M, Bamousa A, Khalil A, AlKattan K. Plasmapheresis before thymectomy in myasthenia gravis: routine versus selective protocols. Eur J Cardiothorac Surg. 2009;35(3):392-7. doi: 10.1016/j.ejcts.2008.11.006.

128. Saeteng S, Tantraworasin A, Siwachat S, Lertprasertsuke N, Euathrongchit J, Wannasopha Y. Preoperative plasmapheresis for elective thymectomy in myasthenia patient: is it necessary? ISRN Neurol. 2013;2013:238783. doi: 10.1155/2013/238783.

129. Blichfeldt-Lauridsen L, Hansen BD. Anesthesia and myasthenia gravis. Acta Anaesthesiol Scand. 2012;56(1):17-22. doi: 10.1111/j.1399-6576.2011.02558.x.

130. Romero A, Joshi GP. Neuromuscular disease and anesthesia. Muscle Nerve. 2013;48(3):451-60. doi: 10.1002/mus.23817.

131. Crespo V, James ML. Neuromuscular disease in the neurointensive care unit. Anesthesiol Clin. 2016;34(3):60119. doi: 10.1016/j.anclin.2016.04.010. 